\title{
TRADUÇÃO
}

\section{NICOLAU DE AUTRECOURT: DUAS CARTAS A BERNARDO DE AREZZO.}

Tradução de

Luis A. De Boni*

\section{Primeira Carta}

Prezado Padre Frei Bernardo:

Com todo o respeito que devo demonstrar-vos devido aos méritos dos frades franciscanos, desejo apresentar nesta carta algumas dúvidas e mesmo, como parece a alguns, os absurdos evidentes - que parecem seguir-se de vossas afirmações. Com a solução de tais dúvidas espero que a mim e a outros se demonstre com mais clareza a verdade.

Li em alguns textos que apresentastes na escola dos frades menores, e aos quais permitistes acesso a todo o verdadeiramente interessado, as proposições que seguem:

A primeira, colocada por vós nos Comentánios às Sentenças (dist. 3, q. 4), diz o seguinte: "O conhecimento intuitivo e claro é aquele pelo qual julgamos que uma coisa existe, independente do fato de ela existir ou não."

A segunda proposição, colocada no mesmo lugar, afirma: "Na sentença: 'O objeto não existe, logo não é visto', não vale a conseqüência, como não vale também esta: 'Isto é visto, logo existe'. Ambas aliás são falsas, como o são estas: 'César está na mente, logo César existe; César não existe, logo não está na mente'."

A terceira proposição, também no mesmo lugar, diz: "O conhecimento intuitivo não requer necessariamente a existência da coisa."

Uma quarta proposição creio poder inferir destas três: "Toda a impressão que temos da existência de objetos exteriores pode ser falsa," pois, segundo vós, ele pode dar-se quer o objeto exista, quer não.

"Nicolau de Autrecourt, chamado de "Hume do século XIV", notabilizou-se por seu espírito crítico, apontando os pontos fracos de diversas doutrinas filosóficas de seu tempo. Envolvendo-se em disputas de alcance teológico, foi condenado, devendo queimar seus livros. Por isso mesmo, são poucas as obras que dele restaram, entre as quais as duas cartas aqui traduzidas, dirigidas ao franciscano Bemardo de Arezzo.

PUCRS. 
Uma quinta proposição segue-se: "Pela luz natural da razão não podemos ter certeza de quando nossa impressão a respeito da existência de objetos exteriores é certa ou é falsa," porque ela, segundo vossas palavras, representa do mesmo modo que a coisa existe, quer exista, quer não exista. Ora, como quando alguém pôs o antecedente, deve pôr o conseqüente que se infere como conseqüência formal daquele antecedente, segue-se que não tendes certeza evidente da existência de objetos exteriores, e assim deveis conceder tudo o que destas afirmações se segue. Ora, é manifesto que não tendes certeza evidente da existência dos objetos dos sentidos, porque ninguém tem certeza de algo conseqüente, provindo de uma conclusão na qual existe uma falácia manifesta. E tal é o caso aqui, pois para vós há uma falácia na sentença: "A brancura é vista, logo a brancura existe."

Mas talvez digais, como me parece que destes a entendas em uma disputa no convento dos pregadores, que da visão não se pode inferir a existência do objeto visto, quando a visão é provocada ou mantida na existência por uma causa sobrenatural; mas que se pode inferir quando provocada por causas totalmente naturais, concorrendo a influência geral do primeiro agente. A isto argumento em contrário: quando de um antecedente colocado na existência por algum agente, não se pode inferir uma conclusão por seqüência formal e evidente, então daquele antecedente não se pode inferir aquela conclusão, não importando por quem venha a ser posta na existência.

Esta afirmação é evidente por um exemplo e pela razão. Pelo exemplo: se a brancura fosse colocada na existência pelo agente $\mathrm{A}$, e não se pudesse formalmente inferir: "A brancura existe, logo a cor existe", também, conseqüentemente, não se poderia inferir que a cor existe, sendo colocada na existência por qualquer agente que seja.

É evidente também pela razão, porque o antecedente em si não se modifica, na dependência daqueles por quem é posto na existência. Do mesmo modo, não se modifica a coisa significada pelo antecedente.

Além disso: se por aquele antecedente, mediante o conhecimento intuitivo, não se pode concluir: "Logo, a brancura existe", então é necessário acrescentar algo ao antecedente, isto é, aquilo que acima destes a entender: que a brancura não está posta ou conservada na existência por um poder sobrenatural. Com isto, porém, chega-se exatamente ao ponto de minha crítica. Quando alguém não está certo de um conseqüente a não ser mediante outro antecedente, do qual não tem certeza que existe assim como está enunciado, pois não é conhecido por seus termos, nem pela experiência, nem deduzido de ambos, mas apenas crido: então tal pessoa não está certa evidentemente do conseqüente. Este é, porém, o caso se se considerar aquele antecedente com sua modificação, como é evidente. Logo...

Além disso, segundo esta resposta, infere falsamente quem infere do antecedente sem aquela modificação acrescentada, como Aristóteles, os filósofos e outros que não acrescentavam esta modificação ao antecedente porque não acreditavam que Deus pudesse impedir o efeito das causas naturais. Segue-se, pois, que não estavam cientes da existência das coisas sensiveis.

Além disso: pergunto-vos se conheceis todas as causas naturais existentes e possíveis, e se conheceis o quanto elas podem e como sabeis, com evidência re- 
duzida à certeza do primeiro princípio, que algo existe, cuja constituição não implica contradição e que no entanto só pode ser feito por Deus? A este respeito gostaria de ser certificado com a certeza da qual falei.

Além disso: dizeis que o conhecimento intuitivo imperfeito pode referir-se pelo modo natural a uma coisa existente. Pergunto pois de vosso conhecimento intuitivo, como estais certo, com a evidência requerida, de quando o conhecimento é perfeito até aquele grau que torna impossivel ser ele conhecimento de uma coisa não existente. Sobre isto quero ser bem esclarecido.

Assim, pois, fica claro e para mim não resta dúvida que de vossos ditos segue-se que deveis dizer que não estais certo da existência do objeto dos cinco sentidos. E, o que ainda de mais grave pode ser sustentado, deveis dizer que não estais certo de vossos atos, isto é, não estais certo se vedes, se ouvis, e até mesmo se tendes ou tivestes alguém ante os olhos. Digo isto partindo do que afirmais acima (I Sent. dist. 3), que vosso intelecto não tem conhecimento intuitivo de vossos atos, e provais do seguinte modo: "Todo o conhecimento intuitivo é claro; mas o conhecimento que vosso intelecto tem de seus atos não é claro; logo..." A este respeito então argumento: aquele intelecto que não está certo da existência das coisas das quais tem um conhecimento mais claro, também não tem certeza daquelas coisas das quais possui um conhecimento menos claro. Ora, como foi dito, não tendes certeza dos objetos, dos quais tendes conhecimento mais claro que de vossos atos. Logo...

Se argumentardes que por vezes um conhecimento abstrativo é tão claro como o conhecimento intuitivo - por exemplo: que o todo é maior que sua parte de nada serve a afirmação, porque dissestes expressamente que o conhecimento que temos de nossos atos não é tão claro como o intuitivo e que também o conhecimento intuitivo, ao menos o imperfeito, não nos dá naturalmente a certeza da evidência. Isto fica claro por vossas próprias palavras. E assim segue-se evidentemente que não tendes certeza evidente de vossas impressões, e, por conseqüência, não tendes certeza que algo seja captadio por vossos cinco sentidos.

Segue-se também que não tendes certeza se uma proposição é verdadeira ou falsa, pois não tendes certeza evidente de que uma proposição existe ou tenha existido. E mais ainda: segue-se que se fordes interrogado a respeito dos artigos da fé, para saber se credes neles, devereis responder: "Duvido", visto que segundo vossas afirmações não podeis estar certo de vosso ato de crer. Confirmo o que estou dizendo, pois se estivésseis certo de vosso ato de fé, isto aconteceria por um destes modos: ou seria mediante o próprio ato, e então 0 ato direto e o ato reflexo seriam idênticos - o que não quereis conceder; ou mediante um outro ato, e então, segundo vossas palavras, não estarieis certo, pois então a contradição não seria maior do que no caso em que existe a visão de brancura e não existe a brancura.

Resumindo o que foi dito, fica claro que deveis afirmar que não tendes certeza a respeito das coisas que estão fora de vós. Não sabeis então se estais no céu ou na terra, no fogo ou na água e, por conseqüência, não sabeis se o céu de hoje é o mesmo de ontem, porque nem mesmo sabeis se existiu céu, como também não sabeis se existe o porteiro ou o papa e, se estas existem, se são os mesmos ou se são sempre homens diferentes em cada momento. Do mesmo modo não conheceis 
o que existe em vós: se tendes barba, cabeça, cabelos etc. Com muito maior razão segue-se então que não tendes certeza das coisas do passado, por exemplo: se lestes, se vistes ou se ouvistes. Além disso: vossas palavras levam à destruição da vida social e política, pois quando as testemunhas depõem sobre o que viram, não podem concluir: "Vimos, logo foi assim." Além disso: pergunto-vos como os apóstolos tiveram certeza de que Cristo morreu na cruz e ressuscitou dos mortos? E o mesmo se pode dizer de todas as outras afirmações.

Desejo que vos expliqueis a respeito de todas estas coisas, e muito me admiro como digais que estais evidentemente certo de certas conclusões mais ocultas como da existência do primeiro motor e outras semelhantes - e no entanto não tendes certeza a respeito daquelas coisas de que falamos acima. Também é admirável, segundo vossas palavras, como acrediteis poder demonstrar que o conhecimento é diferente do conhecido, pois nem tendes certeza de que existe algum conhecimento, nem de que existam proposições e, por conseqüência, de que algumas proposições sejam contraditórias, pois, como demonstrei, segundo vossas palavras não tendes certeza da existência de vossos próprios atos, posteriormente de vossa inteligência, e assim não sabeis se ela existe. No meu modo de ver, de vossa posição seguem-se os mesmos absurdos que da posição dos céticos. Por isso, para evitar tais absurdos, em disputa na aula de Sorbonne sustentei a tese de que estou evidentemente certo da existência dos objetos dos cinco sentidos e de meus atos.

Apresento contra vossas palavras estas e muitas outras objeções, em tal quantidade que parece não ter fim. Suplico-vos, senhor padre, que me ensineis, pois embora seja ignorante, sou contudo desejoso daquele conhecimento que se deve procurar a respeito da verdade.

Saúdo-vos naquele que é luz, e no qual não existe treva alguma.

\section{Segunda Carta}

Reverendo Padre Frei Bernardo:

A profundidade de vossa sutilidade voltaria com justiça a ser admirada por mim, se soubesse que possuís conhecimento evidente das substâncias abstratas, e até mesmo se julgasse que fosse verdade por uma credibilidade fácil. E posso até dizer mais, nem seria necessário que supusesse que tendes verdadeiro conhecimento das substâncias abstratas: contentar-me-ia em supor que o tendes daquelas unidas aos corpos. Por isso, padre, como afirmais que tendes conhecimento evidente de tão elevados objetos cognoscíveis, quero abrir-vos meu espirito duvidoso e angustiado, para que tenhais a ocasião de levar a mim e a outros ao convívio de tão importantes coisas.

E a primeira coisa que deve ser colocada na origem do que se deve dizer é esta fundamental: os contraditórios não podem ser verdadeiros ao mesmo tempo.

A este respeito devem ser feitas duas observações: a) o primeiro princípio, de forma negativa, diz que em relação a ele não há nada anterior; b) o primeiro princípio, de forma afirmativa ou positiva, diz que ele é anterior em relação a qualquer outro. 
Estas duas observações são assim demonstradas por uma só prova: toda a certeza obtida por nós reduz-se a este princípio e ele mesmo não se reduz a nenhum outro, tal como uma conclusão a seu principio. Segue-se logo que ele é primeiro por uma dupla primazia. A conseqüência torna-se conhecida pela definição do nome primeiro, segundo ambas as observações feitas. $O$ antecedente é demonstrado quanto a suas duas partes. Em primeiro lugar, proponho a seguinte conseqüência quanto à primeira parte, isto é, que toda nossa certeza além desta certeza reduz-se a este principio, com relação ao qual vós dizeis que tendes certeza: é possivel, sem qualquer contradição que surja disto, que algo pareça ser de um modo, e contudo não seja; logo, não se está evidentemente certo que seja assim. Está claro para mim, que se admitir-se que o antecedente é verdadeiro, deve-se também conceder que a conseqüência é verdadeira e que, por conseqüência, não se tem simplesmente a certeza evidente a respeito daquilo de que se dizia estar certo.

Disto fica claro que toda nossa certeza reduz-se a este primeiro princípio e que ele não se reduz a um outro, como uma conclusão que se reduzisse a seu princípio. Disto fica claro que tudo se reduz a ele, como foi dito, e segue-se: ele é anterior a qualquer outro que não é ele mesmo; logo, nada é anterior a ele. Por isso, ele é primeiro pela dupla primazia acima mencionada.

Uma terceira observação ainda ocorre: a contradição é afirmação e negação de uma mesma coisa etc., como se costuma dizer comumente.

Deduzo um primeiro corolário destas considerações, qual seja o de que a certeza de evidência obtida à luz natural da razão é certeza simplesmente, porque obtida em virtude do primeiro princípio, ao qual nenhuma verdadeira lei contradiz ou pode contradizer. Por isso, o que é demonstrado à luz natural é demonstrado simplesmente; e não pode ser feito por outra potência que o oposto do conseqüente esteja junto com o antecedente, tal como nenhuma potência pode fazer que os contraditórios sejam verdadeiros ao mesmo tempo.

Um segundo corolário que deduzo a respeito: a certeza da evidência não possui graus, isto é, se há duas conclusões, das quais temos uma certeza evidente, não estamos mais certos de uma que de outra. Como foi dito, toda certeza reduzse ao mesmo primeiro princípio. Por isso, ou aquelas primeiras conclusões reduzem-se ao primeiro princípio de modo igualmente imediato, e então não há como sejamos mais certos de uma do que da outra; ou uma reduz-se mediata, e a outra imediatamente. Mas isto não obsta, porque pela redução feita ao primeiro princípio estamos tão certos de uma como de outra, tal como o geômetra diz que está tão certo da segunda conclusão como da primeira, e assim com relação à terceira e às demais, embora devido às inúmeras deduções não possa à primeira vista estar tão certo da terceira ou da quarta conclusão como está da primeira.

O terceiro corolário que deduzo é de que, excetuada a certeza de fé, não existe outra certeza além daquela do primeiro princípio ou que pode reduzir-se ao primeiro princípio. Só é certeza aquela sob a qual não existe algo de falso, pois se houvesse uma certeza sob a qual existisse algo de falso - tomemos o caso de que houvesse algo de falso - então, como a própria certeza subsiste, segue-se que alguém está certo de uma coisa, cujo oposto sem contradição é verdadeiro. 
O quarto corolário é de que uma determinada forma silogistica é imediatamente reduzida ao primeiro princípio, porque uma conclusão demonstrada ou é imediatamente reduzida - e então temos o que estamos propondo - ou é reduzida mediatamente. Neste segundo caso, ou temos um processo ao infinito, ou é necessário chegar a uma conclusão que se reduz imediatamente ao primeiro princípio.

O quinto corolário: em toda a conseqüência reduzida imediatamente ao primeiro princípio, o consequiente e todo o antecedente ou uma parte do antecedente são realmente idênticos, pois, se assim não fosse, não seria imediatamente evidente que 0 antecedente e $\mathrm{o}$ oposto do conseqüente não podem sem contradição ser simultaneamente verdadeiros.

Sexto corolário: em toda conseqüência evidente reduzivel ao primeiro principio por qualquer quantidade de membros intermediários, o conseqüente é realmente idêntico ao antecedente ou à parte do indicado pelo antecedente. Isto demonstra-se assim: supondo que uma conclusão seja reduzida por três membros à certeza do primeiro princípio, então, conforme o quinto corolário, o conseqüente será realmente idêntico com o antecedente ou com a parte do significado pelo antecedente. $\mathrm{Na}$ segunda conclusão acontecerá o mesmo, segundo o mesmo motivo. Como na primeira conclusão o conseqüente é realmente idêntico ao antecedente ou com a parte do significado pelo antecedente, e dá-se o mesmo na segunda e o mesmo na terceira, segue-se então da primeira até a última conclusão que nestas seqüências ordenadas o último conseqüente será realmente idêntico com o primeiro antecedente ou com parte do significado pelo antecedente.

Conforme estas afirmações, apresentei em outro lugar, entre outras considerações, a seguinte: Pelo fato que se sabe que uma coisa existe, não se pode inferir com evidência certa reduzida ao primeiro princípio, ou à certeza do primeiro princípio, que uma outra existe.

Das muitas provas existentes para tanto, aduzi a seguinte:

Numa seqüência na qual de uma coisa deduz-se uma outra, o conseqüente não é idêntico realmente com o antecedente ou com parte do significado pelo antecedente. Conclui-se disso que tal conseqüência não é conhecida com a evidência acima descrita do primeiro princípio. $O$ antecedente deste argumento é aceito e concedido pelo adversário. A conseqüência aparece pela descrição da contradição, pois ela é a afirmação e a negação de uma mesma coisa etc. Como, pois, agora o conseqüente não seja idêntico realmente com o antecedente ou com a parte do antecedente, é manifesto que, suposto que o oposto do conseqüente e 0 antecedente fossem simultaneamente verdadeiros, não haveria no caso afirmação de uma só e mesma coisa.

Mas Bernardo responde que embora não haja aí, pelo motivo apresentado, uma contradição formal, há porém uma contradição virtual, chamando de contradição virtual aquela da qual se pode inferir evidentemente uma contradição formal.

Contra isto pode-se argumentar claramente com auxílio do quinto e do sexto corolários. Neles foi demonstrado que, em toda a seqüência reduzivel imediata ou mediatamente à certeza do primeiro princípio, é necessário que o conseqüente 
dado por primeiro ou por último seja realmente idêntico com o primeiro antecedente dado ou com parte dele.

O mesmo pode ser demonstrado a partir de outro argumento: Bernardo diz que embora em uma conseqüência, na qual uma coisa é inferida de outra, não haja contrađição formal, há contudo uma contradição virtual da qual se pode evidentemente inferir uma contradição formal. Seja dado o exemplo da conseqüência: "A existe; logo B, existe". Se, pois, destas proposições: "A existe, B não existe" pudesse ser inferida evidentemente uma contradição formal, isto aconteceria ou aceitando o conseqüente, ou a conseqüência de uma destas proposições ou de ambas as proposições. Mas em nenhum dos casos viria a propósito. Ora, as consequiências ou seriam realmente idênticas com os antecedentes, ou não seriam. Se fossem idênticas, não haveria contradição formal entre as próprias conseqüências, pois não haveria no caso a afirmação e a negação de uma só e mesma coisa. 0 mesmo aconteceria com os antecedentes, tal como não haveria contradição formal ao dizer que existe 0 animal racional e que $o$ animal relinchador não existe pela mesma razão. Se, porém, for dito que estas conseqüências diferem de seus antecedentes, procede-se do mesmo modo como acima, no caso das conseqüências não reduzidas à evidência dos primeiros princípios, pois o oposto do conseqüente pode estar sem contradição com qualquer outro significado pelo antecedente. Se for dito que existe contradição virtual, da qual se pode inferir a formal, procede-se como acima. E assim se procederia ao infinito, ou seria preciso dizer que na conseqüência simplesmente evidente o conseqüente é idêntico em significado com o antecedente ou com parte do significado pelo antecedente.

É verdade o que padre Bernardo afirma a respeito deste assunto, que não é verdadeiro dizer que na conseqüência simplesmente evidente seja necessário que o oposto do conseqüente e o antecedente não podem ser simultaneamente falsos, e assim não se opõem de modo contraditório. Isto, porém, não representa de fato nenhum impedimento, pois não quero dizer que o oposto do conseqüente deve ser contraditório ao antecedente, já que em muitas seqüências o antecedente pode significar mais que o conseqüente, embora o conseqüente signifique parte daquilo que o antecedente significa, como no caso desta sequiência: "A casa existe; logo, a parede existe." Por este motivo, o oposto do conseqüente e o antecedente podem ser simultaneamente falsos. Eu, porém, quero dizer que na seqüência evidente $\mathrm{o}$ oposto do conseqüente e $\mathrm{o}$ antecedente ou parte do significado dele opõem-se de modo contraditório. É manifesto que isto acontece em todo o silogismo correto, pois como nenhum termo é recebido na conclusão, se antes não foi recebido nas premissas, o oposto de conclusão e algo significado pelas premissas opõem-se contraditoriamente. Assim deve acontecer em todo o entimema correto, pois o entimema é uma conclusão que só se efetua graças a uma proposição subentendida, e assim é de certo modo um silogismo que reserva algo na mente.

Aduzi também a seguinte razão para a conclusão principal: "Nunca, por força de alguma conseqüência, pode-se inferir maior identidade dos extremos entre si do que a existente nos extremos com relação ao médio, pois que aquela não se infere a não ser em força desta". O oposto pode porém acontecer, se do fato que uma coisa existe se pode com evidência concluir que outra coisa existe, porque o 
predicado e o sujeito da conclusão significam algo realmente idêntico, estes porém não são realmente idênticos com o termo médio, que é posto por outra coisa.

Mas Bemardo argumenta, contra a regra proposta, que a seguinte conclusão segue-se evidentemente com a evidência reduzida à conclusão do primeiro princípio: "A brancura existe; logo, existe uma outra coisa", pois a brancura não pode existir sem que algo a sustente na existência. Do mesmo modo segue-se: "A brancura não existe originariamente; logo, existe uma outra coisa." Da mesma forma: "O fogo é levado próximo à estopa e não há nada a impedir, então haverá calor."

A estas objeções dei muitas respostas em outro lugar. No caso, respondo apenas que se ele viesse com mil objeções deste tipo, então ou deveria dizer que elas não vêm a propósito ou, se vêm, que nada concluem contra mim, porque em tais seqüências, que ele mesmo preparou, o conseqüente é realmente idêntico em seu sentido como todo o antecedente ou com parte dele, e assim não vêm a propósito, porque no caso ou concederia que tais proposições são evidentes, e disto nada se segue contra minha afirmação. Se, porém, disser que o conseqüente não é idêntico com o antecedente ou com parte dele, então, se concedo que o oposto do conseqüente $\mathrm{e} O$ antecedente são simultaneamente verdadeiros, é manifesto que não concedo os contraditórios, pois a contradição é de um só e mesmo. Tal seqüência, então, não é evidente com a evidência do primeiro princípio, pois "evidência do primeiro princípio" significa: se se concede que o oposto do conseqüente encontra-se unido ao antecedente, concede-se que os contraditórios são simultaneamente verdadeiros. Tomemos por exemplo esta conclusão: "A casa existe; logo, a parede existe." Quem concede que a casa existe e que a parede não existe, não concede que os contraditórios são simultaneamente verdadeiros, pois estas proposições não são contraditórias: "A casa existe e a parede não existe", visto que podem ser simultaneamente falsas. Concede, porém, os contraditórios por outro motivo, porque a afirmação de que a casa existe afirma que também a parede existe. A contradição estaria então em dizer que a parede existe e não existe.

Da regra assim enunciada passo a inferir, para quem quer que considere atentamente, que Aristóteles jamais teve conhecimento evidente de outra substância diferente de sua alma, compreendo aqui substâncias como uma coisa diferente dos objetos dos cinco sentidos e de nossas experiências formais. E não o teve porque, se tivesse tido conhecimento de tal substância antes de qualquer processo discursivo - o que não é verdade, pois estes objetos não aparecem evidentemente - então os ignorantes saberiam de sua existência; nem são conhecidos pelo discurso, isto é, inferindo-se das coisas percebidas que existe uma outra, pois da percepção de uma coisa não pode ser inferida a existência de uma outra, conforme diz a conclusão acima.

E se Aristóteles não teve conhecimento evidente das substâncias unidas aos corpos, muito menos o teve das substâncias puramente espirituais.

Disto se segue - quer queiram, quer não queiram, e isto não devem atribuir a mim, mas à força da razão - que Aristóteles em toda sua Filosofia Natural e Metafísica dificilmente teve tal certeza com relação a duas conclusões, e talvez não a 
teve mesmo com relação a uma só. Do mesmo modo, ou até menos, deve ter tal certeza o padre Bernardo, que não deve ser colocado acima de Aristóteles.

E não só não teve conhecimento evidente, mas julgo que nem mesmo teve conhecimento provável - isto não quero afirmar, mas para provar tenho um argumento que não consigo esclarecer: Ninguém tem conhécimento provável de algum conseqüente em virtude de algum antecedente do qual não está evidentemente certo se o conseqüente esteve alguma vez unido simultaneamente com o antecedente. No caso de um conhecimento verdadeiramente provável dever-se-ia observar bem: quando eu colocava a mão no fogo, ele ficava quente, por isso é provável que se agora eu a colocar, ela venha a ficar quente. Mas, de regra acima enuncia$\mathrm{da}$, segue-se que nunca foi evidente para alguém que, colocados os objetos dos sentidos, antes de qualquer consideração discursiva existem certas coisas, e principalmente aquelas que são chamadas substâncias. Segue-se, então, que não temos conhecimento provável da existência delas. Não afirmo esta conclusão. Que alguém responde a este argumento, pois certamente deve haver uma solução.

E como não temos certeza a respeito da existência de uma substância ligada à matéria, a não ser a de nossa alma, fica claro que a conclusão da existência de substância se deduz de um conteúdo no qual se crê, quando alguém nos apresenta um pedaço de madeira ou de pedra. Quando antes de qualquer consideração discursiva temos deles uma impressão sensivel, pode acontecer graças a algum poder, como o divino, que a substância não existe ali; logo, pela luz natural da razão não se pode inferir destas impressões sensiveis que ali haja uma substância. A conseqüência explica-se pelo que foi dito acima; pois foi dito que a conseqüência é evidente porque há uma contrađição, mas pode acontecer que por obra de algum poder o oposto do conseqüente esteja unido ao antecedente. Mas se ele disser que a conseqüência é evidente se se acrescentar ao antecedente que no caso Deus não está fazendo um milagre: recuso o argumento com aquilo que foi dito na primeira carta a Bernardo.

Peço-vos, padre, que recebais estas minhas dúvidas e aconselheis minha ignorância. Prometo-vos que não me obstinarei em fugir da verdade, pela qual apelo com todas minhas forças. 